\title{
EVOLUCIÓN DE LA BANCA EN COSTA RICA: UNA BREVE DESCRIPCIÓN DE SUS ORÍGENES HASTA LA ACTUALIDAD
}

\author{
ARTURO AZOFEIFA CÉSPEDES \\ Universidad Estatal a Distancia, Costa Rica \\ aazofeifa@uned.ac.cr
}

RESUMEN

La banca, en términos generales, es uno de los sectores más importantes en la economía de un país, tanto en el sector privado como en el estatal. Eso se debe a que ejerce un control en las finanzas; a nivel macro, por medio de la promulgación de las políticas económicas de un país y, a nivel micro, ayudando al impulso de la economía desde varios frentes. Entre dichos frentes se encuentra la generación de empleo con buen nivel de salarios y su operativa natural de generar rendimientos al dinero de los ahorrantes y prestar ese dinero a los solicitantes. La banca se puede dividir en dos grandes partes: la banca estatal, que se subdivide en la Banca Central (gobierno) y la banca estatal comercial. Por otro lado, se encuentra la banca privada, que viene a competir con la banca estatal y genera un beneficio para los habitantes de un país.

PALABRAS CLAVE: BANCO CENTRAL, POLITICA MONETARIA, DINERO, GOBIERNO.
ABSTRACT

Banking, in general terms, is one of the most important sectors in a country's economy, both in the private sector and in the state sector. This is due to the fact that it exerts macro-level control over finances through the promulgation of the economic policies of a country, and at a micro-level, helping to boost the economy from several fronts, among them the employment generation with a good salary level and with its natural operative to generate returns to the money of the savers and lend that money to the applicants. Banking can be divided into two main parts: the state bank, which in turn is sub-divided into Central Banking (government) and commercial state banking, and on the other hand private banking, which comes to compete with the state bank generating a benefit for the population of a country.

KEY WORDS: CENTRAL BANK, MONETARY POLICY, MONEY, GOVERNMENT. 


\section{INTRODUCCIÓN}

El siguiente trabajo tiene como objetivo presentar y explicar, de una manera práctica y sencilla, la historia, el desarrollo, la evolución y la actualidad de la banca en Costa Rica. Con esto, se pretende dar un mayor enfoque a cómo se maneja y cómo fue creciendo el sistema bancario nacional hasta la actualidad, pasando por las diferentes etapas de este sector hasta concluir con lo que es hoy en día.

A su vez, se busca conocer el papel del Banco Central, para tener un conocimiento más amplio y con esto poder emitir un criterio de su situación actual a nivel país, con el fin de proponer soluciones reales, si fueran necesarias. Durante el desarrollo de este trabajo se analiza información relevante y ordenada que pretende contribuir a la comprensión de la actualidad bancaria y económica nacional hasta lograr ubicarse en el contexto del tema de una forma clara.

Para cualquier país es de suma relevancia y completamente indispensable contar con un banco central que se encargue de manejar los hilos de la economía y sus diferentes necesidades, buscando soluciones y aplicando las políticas económicas de una manera certera y eficiente. La economía se basa en aprovechar eficientemente recursos insuficientes, por lo que es muy importante que la toma de decisiones sea la más idónea y correcta para evitar alterar la estabilidad social y económica de los países, evadiendo llegar a puntos críticos, como recesiones económicas, y lograr contar con índices de desarrollo económico y social de primer mundo.

Para lograr esos objetivos, es posible utilizar diferentes herramientas que se han venido implementando e investigando en todo el mundo a través del tiempo. Con ello, se potencian soluciones que han venido a significar mejoras a los diferentes problemas económicos y que han surgido ya sea a raíz de la investigación previa de grandes intelectuales o a raíz de decisiones tomadas en momentos cruciales en plena crisis y que finalmente sirvieron como una solución inmediata al problema. Tampoco se debe olvidar que malas decisiones que se tomaron en el pasado posteriormente trazaron los diferentes cursos de acción a seguir.

El Banco Central de Costa Rica, claramente, tiene objetivos principales y primordiales, políticas a seguir y leyes que cumplir, además de emitir regulaciones a los diferentes agentes financieros. Esto lleva al conocimiento de las funciones más importantes de un banco central y cuáles políticas económicas utiliza y por medio de cuáles herramientas o instrumentos logran aplicarlas. Todo esto para alcanzar un manejo idóneo de los temas bancarios, poniendo límites a los distintos participantes en el sector financiero pero, también, implementado sistemas que faciliten su trabajo. Todo esto llevará a un importante desarrollo del sector bancario y, a su vez, derivará en bonanza económica a nivel macro o a nivel país.

Es importante saber que el Banco Central, además de ser el principal ente fiscalizador y promulgador de políticas económicas, también es el banco del Estado y, como tal, quien lleva las cuentas del país. Si se quiere, se puede percibir al Estado como una gran empresa en donde su administrador financiero es el Banco Central. A continuación, se desarrollan los principales aspectos antes comentados para con esto cumplir con el principal objetivo de la investigación: describir brevemente la evolución de nuestra banca a lo largo de la historia de Costa Rica.

\section{METODOLOGÍA}

Para este trabajo se realizó una revisión de la literatura publicada en los últimos diez años acerca de los elementos más importantes relacionados con la historia de la banca nacional e internacional: sus funciones, estructura, importancia y otros aspectos vinculados. Se tuvieron en cuenta, en su mayoría, estudios de los años 
2007 a 2017 y se incluyeron solo aquellos originales y que se consideró brindarían más valor a esta propuesta, seleccionando para ser revisados aquellos autores o documentos más importantes vinculados con el tema.

Otro factor que caracteriza la literatura utilizada en este trabajo, es la importancia de sus autores. Muchos de ellos son grandes referentes del tema de estudio. También, su obra es frecuentemente citada en trabajos académicos y de investigación: libros, artículos, ensayos, trabajos finales de graduación, entre otros. Asimismo, se revisaron las bases de datos Digitalia, Ebsco, E-libro y Proquest, en los idiomas inglés y español.

\section{HISTORIA DE LA BANCA}

Los bancos, en general, son instituciones que se constituyen de acuerdo con reglas específicas y trabajan con recursos financieros. Para lograr esto, captan y resguardan depósitos hechos por los individuos y las empresas. Al mismo tiempo, usan esos recursos para conceder préstamos, bajo cuenta y riesgo propios, actividad que se puede señalar como intermediación financiera.

Un Banco Central es el organismo que emite, gestiona y administra la moneda de un estado y ejecuta el cargo de prestamista de bancos. Adicionalmente, intervienen la política monetaria, los créditos y el sistema cambiario del país, los cuales incluyen el dinero circulante, las tasas de interés y el tipo de cambio respectivamente. Mishkin (2008, p. 394) señala que:

"El Banco Central es la máxima autoridad bancaria de un país. Aunque todos los objetivos de la política económica están a su disposición, su prioridad es el control de la inflación, la estabilidad de los precios y el tipo de cambio".

Propiamente desde la perspectiva histórica, antes del siglo XVII, dinero mercancía (oro, plata y cobre) se usaba para realizar la mayoría de las transacciones entre los individuos. Esto ocasionaba problemas, ya que algunos metales fluctuaban más que otros. También, existían las promesas de pago posteriores en muchos pueblos de Asia y Europa.

Durante la edad media, se usó un tipo de banco central en Europa en el que las promesas de pago eran su mayor herramienta para la circulación de dinero, ya que estas eran muy respetadas. Lo más cercano a un banco central fue el Banco de Estocolmo. Este estableció un servicio de custodia sobre metales con valor y entregaba recibos a los dueños de los metales que guardaba en sus bóvedas. Al transcurrir el tiempo, el banco notó que los metales pasaban mucho tiempo en las bóvedas sin ser reclamados por sus dueños originales, por lo que se decidió prestarlos a terceras personas. De esta forma, el banco se convirtió en un prestamista sin utilizar sus recursos propios.

El primer Banco Central formalmente constituido fue el Banco Central de Inglaterra en 1694 y fue nacionalizado hasta 1946. Al igual que muchos otros bancos centrales, en sus inicios fue comercial y privado. El Banco de Inglaterra surge por la necesidad de reconstruir al país después de la batalla con Francia en 1694; sin embargo, el gobierno se encontraba sin dinero. Como resultado, se creó un banco que dio al gobierno 1.2 millones de libras a cambio de posesión exclusiva de sus balances financieros y bonos.

Los bancos centrales de Latinoamérica también aparecieron con el tiempo. En un principio, la ejecución de las políticas monetarias y de equilibrio financiero en casi todos los bancos centrales eran actividades hasta cierto punto informales y no tenían muchos controles. Muchos bancos centrales no tenían la independencia de los gobiernos y eran simplemente instituciones que emitían dinero para los gobiernos deseosos de financiar sus déficits mediante la inflación.

Inicialmente, los bancos centrales de Latinoamérica obedecían las órdenes de los gobiernos en su 
totalidad, lo que causó un incremento en la inflación. Las reservas se vieron afectadas con regularidad como resultado de la falta de control de las políticas de tipo de cambio fijo y de las altas tasas de inflación. Con el tiempo, los bancos centrales de la región se fortalecieron a través de leyes de autonomía, la aceptación de nuevas reglas en la política monetaria (como el establecimiento de objetivos de inflación) y más claridad en el proceso de toma de decisiones. Todo ello ha sido resultado de un creciente acuerdo entre los responsables de la política monetaria y los gobiernos.

Particularmente en Latinoamérica se han producido muchos cambios en la forma de operar de los bancos centrales. Después de extensos periodos de déficits públicos, costeados mediante la emisión de dinero, lo que lleva a una alta inflación, a los bancos centrales se les concedió la independencia para la toma de decisiones de política monetaria. Estas medidas le han dado mucha flexibilidad para establecer regímenes de política monetaria semejantes a los mejores a escala internacional, capaces de diseñar políticas orientadas al logro de objetivos de estabilidad monetaria y del sistema financiero.

El proceso de renovación de los bancos centrales de Latinoamérica se apoyó en un gran convenio fiscal y también en el fortalecimiento del sistema financiero a través del perfeccionamiento de las leyes y la supervisión. Esto hizo que las tasas de inflación de la mayoría de los países de la región se redujeran a tasas de una sola cifra y se lograra alcanzar tasas de crecimiento más elevadas y estables que en el pasado.

\section{FUNCIONES DEL BANCO CENTRAL EN EL MUNDO}

Queda claro que la autoridad monetaria principal de un estado responsable de proclamar y hacer que se cumpla la política monetaria, así como de controlar el sector bancario es el Banco Central. Se trata de un banco oficial que constituye el eje del sistema financiero y la cúspide del sistema bancario. Como se mencionó antes, el concepto de banco central aparece tardíamente en muchos países, habitualmente producto de la nacionalización de algún banco privado, cuando a alguno de estos bancos se le otorgó el derecho de emitir billetes y monedas de curso legal y el monopolio para llevar a cabo las operaciones bancarias del país.

Las principales funciones de un banco central son las siguientes:

- Dominar y administrar el monopolio de emisión de los billetes y monedas de una nación y la efectiva medición y regulación del dinero que se circula.

- Ser banquero del Estado. Proveer de fondos a la Administración Pública y encargarse de la emisión y el reembolso de la Deuda Pública.

- Ejercer como banquero de otros bancos, lo que significa otorgar créditos (mediante la tasa de redescuento) y custodiar el encaje mínimo legal proveniente los demás bancos. Además, realizar las tareas de observación de los bancos, cajas de ahorro, regular el crédito y demás instituciones financieras que se dedican a realizar actividades bancarias para asegurar el cumplimiento de las disposiciones legales.

- Resguardar en sus arcas las reservas monetarias acumuladas que posee el país.

- Dar consultorías y asesorar al gobierno en temas de naturaleza monetaria y crediticia.

Aparte de los factores mencionados, es importante que el Banco Central tome en cuenta otras áreas cuando ejerce sus funciones, tales como el equilibrio interno, la estabilidad del poder de compra, maximizar los factores productivos $y$, en 
general, ayudar al desarrollo económico del país. Conservar el equilibrio externo sigue siendo muy importante, sobre todo, en un mundo cada vez más globalizado. La adecuada asignación de recursos productivos entre el país y el exterior es de suma importancia en la competencia internacional. No importan las tendencias monetarias por las cuales se incline el país, se puede expresar que se trata de preservar la solvencia financiera externa, dándole la posibilidad al país de adquirir tanto los bienes y servicios como el crédito y los capitales que necesita del resto del mundo para lograr sus objetivos.

El sistema económico de un país obedece, al mismo tiempo, a las condiciones internas. Por lo tanto, es una tarea para el Banco Central estabilizar el poder adquisitivo de la moneda. Esto intenta controlar la emisión inorgánica de dinero. Dicha tarea puede contradecir en conservar la estabilidad externa hasta cierto punto; por ejemplo, en el caso que se trate de controlar una inflación creciente con una balanza de pagos positiva, podría darse una inestabilidad externa.

Otro aspecto importante a considerar es la máxima utilización de los recursos productivos. Este aspecto indica que la política monetaria no puede estar separada de la realidad productiva, ya que obligatoriamente hacia ella van sus objetivos. Se trata de no desplazar factores productivos como la mano de obra, que juega un papel muy importante en el desarrollo.

La responsabilidad del banco central no solo radica en el control de la política monetaria, sino que debe tener en cuenta los efectos en el resto del sistema. Por esta razón, debe crear las condiciones, los escenarios y estímulos financieros que crea favorables para obtener y mantener una tasa optima de crecimiento de la economía a lo largo del tiempo.

La discrepancia de los objetivos previamente establecidos bajo situaciones atípicas debe ser resuelta por el Banco Central, según los criterios que predominen en el plan general; es decir, que haya una relación entre las políticas de desarrollo y de la forma del gobierno.

\section{LA BANCA CENTRAL Y SU PARTICI- PACIÓN EN LAS CRISIS ECONÓMICAS}

La importancia de la Banca Central crece en los períodos de crisis que afrontan los países, convirtiéndose en uno de sus principales objetivos la estabilidad de los precios. Las autoridades de este ente responsables de realizar los cálculos de crecimiento del país. La intervención del Banco Central de Costa Rica ha sido de una política monetaria restrictiva, complicando la situación de los ciudadanos al implementar:

- Tasas de interés altas: esta medida afecta a los deudores, perjudicando el crecimiento incluso de las PYMES.

- Desempleo: ligado al punto anterior, el aumento de las tasas de interés reduce el crecimiento en el país para generar empleo.

Basándose en los puntos anteriores, se evidencia que, en la política económica nacional, es necesario incluir el bienestar social, así como la distribución de la riqueza y no solo basar su participación en la estabilidad de precios.

El Banco Central, en su Programa Macroeconómico 2018-2019 proyecta un crecimiento en la economía costarricense del 3.6\% al 3.9\%, a pesar de reconocer una compleja situación fiscal; este es el factor de riesgo más difícil de controlar. Considerando la problemática actual del país, el Banco Central de Costa Rica solicitó al Fondo Monetario Internacional (FMI) evaluar la estabilidad del sector financiero.

Este estudio arrojó como resultado que el país no estaría listo para afrontar una crisis financiera. Los 
siguientes fueron los ocho puntos que el FMl resaltó en su estudio:

- Supervisión Bancaria y Gobierno Corporativo. Carece de detección temprana del riesgo y adopción de medidas correctivas.

- Controlar el cambio del enfoque de supervisión. Al enfoque de supervisión basado en riesgos.

- Red de Seguridad Financiera es incompleta. El FMI recomienda un apoyo inmediato de liquidez, así como un marco de garantía de depósitos.

- Urgen modificaciones en pensiones. Se sugieren modificaciones para logar su estabilidad.

- Riesgo por dolarización. Se considera un riesgo cambiario bajo, debido a la intervención del Banco Central de Costa Rica en el mercado de divisas.

- Deuda Pública Domina Mercado de Valores. El mercado secundario no ha logrado desarrollarse debido a la concentración de deuda pública.

- Monitoreo y Mitigación de Riesgos. Las autoridades deben contar con las potestades y mecanismos adecuados y así salvaguardar la estabilidad financiera.

- Promover la Inclusión Financiera. Elaborando una estrategia nacional por parte de autoridades e interesados y así realizar un diagnóstico común.

\section{REFORMAS Y PROPUESTAS DE RE- FORMAS}

\section{UNIÓN EUROPEA}

La nueva normativa microprudencial recae sobre las Autoridades Europeas de Supervisión (ESA, por sus siglas en inglés), la cual sustituye a los comités consultivos con una autonomía presupuestaria y con fundamento jurídico firme para coordinar los enfoques de regulación y supervisión.

En cuanto a la supervisión macroprudencial, recae sobre el Consejo Europeo de Riesgo Sistemático (CERS), con el fin de prevenir o mitigar el riesgo sistemático en la estabilidad derivado de evolución del sistema financiero y de la economía en general y tiene la autoridad de formular recomendaciones y advertencias sobre riesgos sistemáticos. Depende, en gran medida, de la experiencia técnica de los bancos centrales.

\section{ESTADOS UNIDOS}

El control macroprudencial lo ejerce la ley DoddFrank y está a cargo del Consejo de Supervisión de la Estabilidad Financiera (FSOC, por sus siglas en inglés). Esta instancia carece de autoridad normativa o ejecutiva, pero está facultada para recomendar de manera pública.

\section{POLÍTICA PREVENTIVA}

\section{LA PROVISIÓN DE PRÉSTAMOS DE EMERGENCIA}

El banco central será la autoridad independiente de prestar al sector privado, limitado por requisitos explícitos sobre la naturaleza de la garantía y por la fijación del precio de las operaciones. En otros países, el juicio será discrecional mientras que otros el gobierno se involucra en la toma de decisiones cuando se trata de operaciones distintas de las normalizadas. 


\section{REGÍMENES ESPECIALES DE RESOLUCIÓN PARA ENTIDADES FINANCIERAS Y BANCOS EN QUIEBRA}

El parlamento británico estableció un régimen especial de resolución (SRR), el cual permite a las autoridades intervenir antes de declararse la insolvencia y así trasladar total o parcialmente las actividades de un banco con amenaza de quiebra a otra entidad financiera.

\section{ASUNTOS DE RENDICIÓN DE CUENTAS Y DE TRANSPARENCIA RELACIONADOS CON ACTUA- CIONES EN MATERIA DE GESTIÓN DE CRISIS}

En Estados Unidos, la nueva ley exige que la Reserva Federal notifique de manera inmediata con informes periódicos sobre los nombres de los prestatarios, el importe del préstamo y las garantías para, así, compartir la información con los miembros de mayor rango del Congreso.

\section{RIESGOS FINANCIEROS RESULTAN- TESDELASMEDIDASDEEMERGENCIA}

En su búsqueda de la estabilidad económica, los bancos centrales podrían estar asumiendo riesgos financieros por falta de autoridad o por falta de capacidad para asumir riesgos. Teniendo clara la posibilidad de un quebranto financiero, han creado diferentes mecanismos:

- Fuerte capitalización del banco central. Esto le permite en actividades con riesgo financiero sin recurrir al presupuesto estatal.

- Transferencias de riesgo, tanto de activos y pasivos asociados a una transacción en específico, así como mecanismos de indemnización establecidos de manera automática que se activan al momento en que el banco central realice actividades de riesgo.
- Recapitalización como mecanismo de limpieza una vez ocurrido el evento de riesgo, manteniendo los pasivos y los activos en los libros del banco central.

Incluyendo al banco central, un buen esquema de gobierno sería:

- Claridad y especificación de los objetivos.

- Adecuación de las potestades y los recursos.

- Estrecha alineación de los objetivose incentivos.

Los bancos centrales tienen como objetivo preservar la estabilidad monetaria y así promover la estabilidad financiera. Esto se logra participando en servicios bancarios de préstamos y de gestión de activos, así como la deuda al Gobierno. Por ello, en ocasiones realiza estudios y asesora sobre asuntos económicos y de desarrollo.

\section{LA BANCA EN COSTA RICA}

En el caso de Costa Rica, la evolución de la banca se inició a finales del siglo XIX. Los cafetaleros decidieron expandirse y vender su producto en los mercados internacionales y se dio la necesidad de expandir sus negocios utilizando diferentes medios de financiamiento. En ese momento, la banca privada inglesa se hizo presente para proporcionar el crédito necesario para que los cafetaleros se expandieran. Luego, en 1857 se estableció el Banco Nacional Costarricense, seguido por el Banco Nacional de Costa Rica en 1859 y el Banco Anglo Costarricense en 1863. Adicionalmente, entre 1857 y 1876, se crean otros bancos privados y estatales. En esta época los bancos privados sufrían de mucha incertidumbre, ya que no podían ofrecer una garantía al inversionista; además, muchos de ellos tenían el poder de emitir dinero cuando quisieran. 
Las primeras legislaciones se dieron para 1896, al emitirse la Ley de la Moneda. Para 1900 entra en juego el Patrón de Oro, dando oportunidad a cambiar la unidad monetaria del "peso" al "colón". De aquí, surge para abril de 1900 la primera Ley de Bancos, que resalta una ligera intervención por parte del gobierno para fiscalizar la banca privada.

En 1914, propiamente el 9 de octubre, es fundado el Banco Internacional. Esta figura empieza una competencia con la banca privada para lo correspondiente al otorgamiento de créditos. Como consecuencia de este movimiento, nace en 1915 el Banco Crédito Agrícola de Cartago.

En 1929, Costa Rica se ve afectada de manera directa por la crisis mundial provocada por el desarrollo de los países industriales. Debido a las consecuencias de la crisis, surge la necesidad de una legislación que unifique a todos los bancos, estatales y privados, bajo la figura de un Banco Central como orientador y propulsor de la economía costarricense.

La quiebra de muchos bancos y el incremento de la actividad bancaria del país llevaron, en 1945, a la fundación de un Banco Central que operara como mayor autoridad que las instituciones existentes. Hasta ese año, la política monetaria estaba bajo la responsabilidad del Banco Nacional de Costa Rica, el cual fue establecido a finales de 1936 al reajustarse el antiguo Banco Internacional que fue fundado en 1914.

La creación del Banco Central se promulgó en la Ley 1130, el 28 de enero de 1950. En esta ley se le estableció como un órgano independiente y rector de la política económica y monetaria. Para el 23 de abril de 1953 fue promulgada la Ley 1552, Ley Orgánica del Banco Central de Costa Rica (esta se sustituye el 3 de noviembre de 1995 por la Ley 7558).

Los principales objetivos del Banco Central de Costa Rica siguen siendo, igual que en un principio, conservar estable la moneda y establecer mecanismos para poder controlar la inflación. El Banco
Central ha estado históricamente comprometido a custodiar las reservas del estado, administrar el crédito al sector público y manejar las emisiones de deuda pública.

Asimismo, debe promover la firmeza, estabilidad y eficiencia del sistema financiero, vigilando el funcionamiento de los pagos internos y externos. Estos objetivos permiten crear un ambiente predecible para la toma de decisiones, contribuyendo a amortiguar los efectos de los ciclos económicos y creando las bases para un desarrollo sostenido del país.

Para lograr sus objetivos, el Banco Central tiene, entre otras, la facultad de regular la cantidad de dinero en circulación y el crédito en la economía, de tal manera que sean suficientes para que los individuos, empresas e instituciones gubernamentales lleven a cabo sus transacciones. Por otro lado, el Banco Central realiza informes y mantiene publicaciones periódicas de naturaleza estadística e informativa. Los informes oficiales del Banco Central acerca de la situación del país tienen un gran efecto sobre las expectativas empresariales y las perspectivas del gobierno que influyen, por tanto, en las decisiones de inversión privada y de gasto público a futuro.

Del mismo modo que es responsable por la política monetaria, debe velar por que las transacciones que hacen hacia fuera del país tampoco constituyan riesgos que pudieran afectar la situación económica interna y, de esta forma, otro de los temas de interés del banco tiene que ver con el precio del dólar y las operaciones cambiarias internacionales.

\section{ORGANIGRAMA DEL BANCO CENTRAL}

Para tener un mejor entendimiento de las labores de esta importante institución, resulta conveniente analizar su estructura organizacional: 


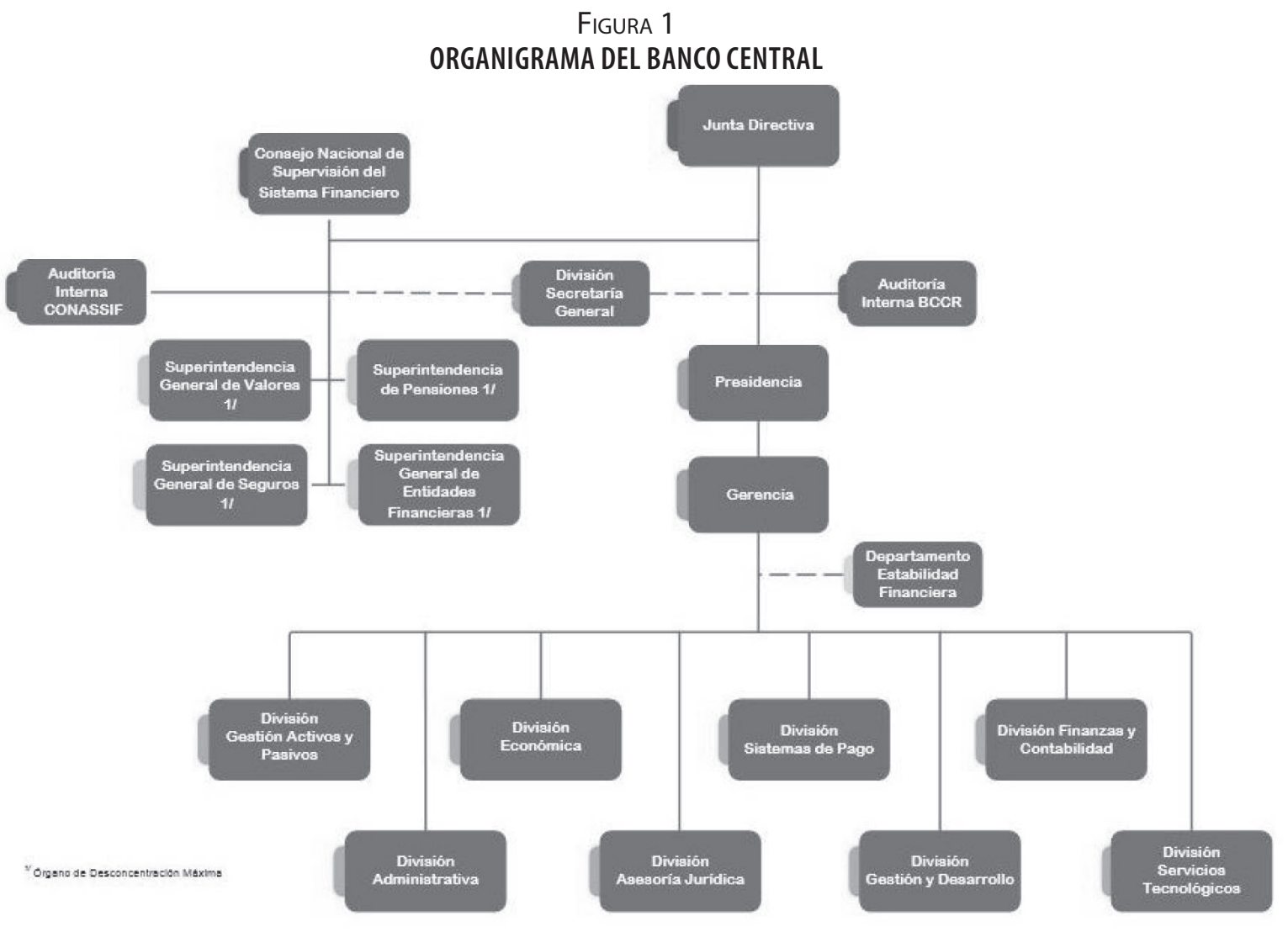

Fuente: Tomado de Banco Central de Costa Rica (2019).

\section{OBJETIVOS DEL BANCO CENTRAL}

El Banco Central fue creado con una misión, visión y objetivo específico, a saber:

Misión. Contribuir al desarrollo de la economía costarricense procurando la estabilidad de precios.

Visión. Ser un banco central reconocido por la sociedad costarricense y la comunidad internacional por su eficiencia, transparencia, credibilidad y capacidad para mantener una inflación baja y estable.

Objetivo. Los principales objetivos del Banco Central de Costa Rica son mantener la estabilidad interna y externa de la moneda nacional y asegurar su conversión a otras monedas.
El Banco Central de Costa Rica buscará el control de la inflación será el responsable de controlar la inflación.

La Ley Orgánica del Banco Central (1995) establece en su Artículo 3 como funciones esenciales del Banco Central:

- El mantenimiento del valor externo y de la conversión de la moneda nacional.

- La custodia y la administración de las reservas monetarias internacionales de la Nación.

- La definición y el manejo de la política monetaria y cambiaria. 
- La gestión como consejero y banco-cajero del Estado.

- La promoción de condiciones favorables al robustecimiento, la liquidez, la solvencia y el buen funcionamiento del Sistema Financiero Nacional.

- La emisión de billetes y monedas, de acuerdo con las necesidades reales de la economía nacional.

- La determinación de políticas generales de crédito y la vigilancia y coordinación del Sistema Financiero Nacional.

- La custodia de los encajes legales de los intermediarios financieros.

- El establecimiento, la operación y la vigilancia de sistemas de compensación.

- El establecimiento de las regulaciones para la creación, el funcionamiento y el control de las entidades financieras.

- La colaboración con los organismos de carácter económicodelpaís, paraelmejorlogrodesusfines.

- El desempeño de cualesquiera otras funciones que, de acuerdo con su condición esencial de Banco Central, le correspondan.

Históricamente, al Banco Central se le ha dado la responsabilidad de custodiar las reservas del Estado, así como administrar la deuda pública.

En general, en todos los países, las funciones del Banco Central consisten en:
- Política Monetaria. Analizar la situación económica del país, diseñar las estrategias de la política monetaria y así garantizar la estabilidad monetaria.

- Regulación de la circulación fiduciaria. Poner en circulación los billetes y las monedas suministrando efectivo a las necesidades del comercio.

- Banco de Bancos. Custodiar la reserva de la banca privada.

- Control e inspección. Diseñar las normas de funcionamiento de la banca privada. Autorizar la apertura de nuevos bancos, inspeccionar su funcionamiento.

- Control de Cambio. Gestionar los cambios de divisas. Ser el encargado de la Balanza de Pagos.

- Asesoramiento. Elaborar informes y publicar periódicamente documentos de carácter estadístico.

Se podría decir que la inflación es el aumento general y sostenido del índice de precios al consumidor (IPC). Esto quiere decir que un aumento en los precios debe de ser representativo del IPC y, además, durante un periodo largo de tiempo. El Banco Central Europeo (2016) define lo siguiente: "Se habla de inflación cuando se produce un aumento generalizado de los precios que no se limita a determinados artículos" (s. p.).

Cuando una economía está orientada al libre mercado, el precio de un producto o de un servicio es fijado por la oferta y la demanda. Fundamentalmente, se logra un equilibrio entre lo que un sector puede producir a un precio dado y lo que la otra parte desea adquirir. A esta situación se le conoce como un precio de equilibrio. 
Pero la inflación no es la única situación que se puede dar por los cambios en los precios. La deflación es la situación inversa y consiste en el desplome general del nivel de los precios de bienes y servicios que conforman el índice de precios al consumidor (IPC). Comúnmente, la deflación es causada por la disminución de la demanda, lo cual puede constituir un problema mucho más peligroso que la inflación, porque una caída de la demanda se va a ver traducida en una caída general de la economía del país.

La deflación puede desatar una situación de la cual es difícil de emerger, ya que las empresas tienen que vender sus productos para cubrir al menos sus costos de producción, para lo cual deben vender a los precios más baratos. En dicho caso, las empresas tienen que operar con márgenes de ganancias bajos e incluso negativos, proceso del cual muchas no logran recuperarse y deben de cesar sus operaciones.

Para combatir la deflación se debe devaluar la moneda. Para ello, se debe emitir y colocar más dinero en circulación, acompañado con una reducción de la tasa de interés, lo cual estimula el crédito de consumo y de inversión, reavivando de esta forma la demanda.

Al contraerse las tasas de interés, ya no es atractivo mantener el dinero en las diferentes entidades financieras y la gente optará por invertirla o gastarla. Esta situación puede beneficiar a los empresarios, ya que pueden expandir sus empresas, proceso que se complica por los efectos de la deflación.

Adicionalmente, existe otro fenómeno llamado estanflación. Es un fenómeno económico en el que se da la combinación de inflación y desempleo; cuando se producen simultáneamente son catastróficos para un país. En otras palabras, es cuando la economía de un país se encuentra en recesión y a la vez existe inflación.
La estanflación produce un ambiente difícil donde se dan situaciones como el incremento de precios, crecimiento del desempleo y retraso económico que pueden llevar al país a un entorno muy grave de empobrecimiento.

Como ya se ha mencionado, el principal objetivo de cualquier banco central es el de mantener la estabilidad de precios a través del control de la inflación. Para controlar la inflación, el Banco Central debe de ser muy cuidadoso con las emisiones inorgánicas de dinero que no están respaldadas con aumentos en la producción de bienes y servicios, ya que esto llevaría a un exceso de liquidez y a un aumento de los precios en general.

Otro tema que le concierne al Banco Central de Costa Rica es cuidar la estabilidad externa del país que se ve reflejada en la balanza de pagos. Dicha balanza es el registro constante de todas las transacciones que se llevan a cabo entre los residentes del país y los del resto del mundo. Cada vez que se realiza una transacción se añade a la balanza de pagos como un crédito o un débito. Un crédito es una transacción que hace que el país reciba un pago extranjero y un débito es una transacción que lleva a un pago a otros países. Sus elementos más importantes son la cuenta corriente, la cuenta de capital y la cuenta de las reservas.

La estabilidad externa también se puede controlar mediante el tipo de cambio, que es el precio de una unidad monetaria extranjera expresado en términos de la moneda nacional. Existen dos tipos de cambio: el nominal y el real. El tipo de nominal real es el precio relativo de dos monedas, expresado en unidades monetarias; es decir, la relación a la que una persona puede intercambiar la moneda de un país por los bienes de otro país. El tipo de nominal real precio relativo de dos canastas de consumo y se usa para calcular el poder adquisitivo de una moneda en el extranjero; es decir, el precio de los bienes del país extranjero expresado en términos de bienes locales. Se puede explicar cómo una variable que 
se utiliza como medida de la competitividad de un país con relación a otro.

Existen regímenes de cambios fijos, flexibles o de flotación. El régimen cambiario fijo es aquel en el que el Banco Central establece el tipo de cambio fijo que desean mantener. Normalmente, se permite la flexibilidad dentro de ciertos límites establecidos cerca del tipo de cambio determinado. Sin embargo, la flexibilidad está más limitada de lo que estaría si el Banco Central hubiera preferido un régimen flexible.

El tipo de cambio flotante o flexible, es un régimen en el que se consiente que el valor de una divisa oscile respecto al valor de otras divisas de acuerdo con la oferta y demanda de divisas en el mercado. La importancia del tipo de cambio radica en que permite la conversión de moneda de un país en moneda de otro país, haciendo más fácil el comercio de bienes y servicios y también el movimiento de los recursos financieros entre países. Además, permite la comparación de canastas de productos y precios similares en diferentes países. Generalmente, la diferencia de precios entre productos similares determina qué productos y adonde se van a exportar.

Las exportaciones e importaciones de bienes de servicios se han convertido en uno de los factores más importantes en el crecimiento de los diferentes países, principalmente en el contexto de globalización vigente. Por ello, cualquier variación del tipo de cambio que ocurra se convierte en un factor determinante en el comercio internacional. Dichas variaciones de precios pueden provocar cambios en los hábitos de consumo que van a causar variaciones de la demanda de productos y servicios por parte de los consumidores extranjeros $y$, efectivamente, van a tener un efecto en las exportaciones y en el aumento del producto interior bruto (PIB).

El crecimiento económico es uno de los objetivos de todo país. Involucra un aumento considerable de los ingresos y de la forma de vida de todas las personas que viven en una sociedad. Existen muchas maneras mediante las cuales se puede medir el crecimiento. Se podría tomar como referencia la inversión, las tasas de interés, el consumo, las políticas gubernamentales. Todas estas variables son instrumentos que se utilizan para medir el crecimiento. Es importante medir crecimiento para determinar qué tan lejos o cerca está el país de ser desarrollado.

La forma más fácil y certera de medir el crecimiento económico es mediante el Producto Interno Bruto, el cual se puede definir como la producción de bienes y servicios realizada en un país durante un periodo de tiempo determinado.

Paralelamente, con el concepto de crecimiento económico existe otro más amplio que incluye variables no considerados por el PIB. Este es el concepto de desarrollo económico, que envuelve, además de aspectos como el nivel de producción de bienes y servicios, aspectos estructurales como la educación de las personas, tasas de criminalidad, indicadores de mortalidad, esperanza de vida, etc. También, se toman en cuenta otros aspectos como la inflación, ingreso per cápita, tasa de desempleo, pobreza, indicadores ambientales, etc. El Banco Central también juega un papel importante en el crecimiento económico, ya que mediante la política monetaria puede influir en las tasas de interés para incentivar la inversión y esta va a tener como consecuencia un crecimiento económico positivo.

Aunque el Ministerio de Hacienda es responsable por la tasa de desempleo, el Banco Central indirectamente también influye en esta tasa mediante sus decisiones de política monetaria expansiva o restrictiva. Generalmente, existe una relación inversa entre desempleo e inflación, lo que significa que en escenarios donde la inflación es baja, las tasas de desempleo 
tienden a ser altas y viceversa. Existen casos en los que tanto una alta inflación y un alto desempleo pueden existir. Por ejemplo, el caso de una inflación importada o de demanda agregada que pueden causar un incremento acelerado de los costos de producción que va a aumentar el nivel de precios y por fuerza va a disminuir el consumo, situación que llevaría a un alto desempleo en algún momento.

Otro de los objetivos del Banco Central es promover la estabilidad del sistema financiero. El sistema financiero se puede definir como el grupo de instituciones que existen en un país y que tienen como propósito captar y canalizar los recursos que generan los prestamistas o personas superavitarias hacia los prestatarios o personas deficitarias. La Enciclopedia Financiera (2015) indica que "El Sistema Financiero es un marco institucional en el que los agentes con déficit de fondos obtienen los recursos sobrantes de los agentes con superávit de fondos" (s. p.).

El sistema le da a las personas superavitarias oportunidades de ahorro y de inversión. Sin embargo, es importante mencionar que es elemental que estas personas y entidades estén al tanto de que muchas opciones que se ofrecen presentan riesgos que, en muchos casos, son desconocidos por los dueños de los recursos. Por tanto, se recomienda un buen asesoramiento que pueda brindar todas las alternativas y también advertencias sobre los mejores y peores escenarios de las diversas operaciones que se presentan en el mercado.

Con el objetivo de practicar un control riguroso dentro del sistema financiero existen instituciones reguladoras del sistema financiero que se dan la tarea de supervisar el cumplimiento de las leyes para asegurar la estabilidad del sistema. El Banco Central es una de estas instituciones que se encarga de velar por el buen funcionamiento de las instituciones financieras.
Es claro que el Banco Central tiene muchos objetivos que cumplir, pero en la práctica es muy complicado poder alcanzarlos todos. Por esto, el Banco Central debe dar prioridad a ciertos objetivos y dejar a otros de lado, ya que puede que algunos de ellos no vaya de la mano con otros previamente establecidos y tal vez de mayor importancia.

\section{MECANISMOS DE GOBERNANZA PARA LA FUNCIÓN DE POLÍTICA MO- NETARIA}

- Concesión de independencia. Al Banco Central se le otorga independencia con el fin de ejercer sus potestades para promover el bienestar público; esto dentro de un marco legislativo.

- Establecimiento de objetivos. El objetivo principal es la estabilidad de precios, pero los objetivos no deben ser estrechos con el fin de no reducir su flexibilidad para adaptarse a nuevas circunstancias.

- Régimen de tipos de cambio. Por lo general, los bancos centrales participan de la elección del régimen cambiario y en la política del tipo de cambio, pero sin poder de decisión de manera unilateral.

\section{UNMARCOENLAREGIÓNDELRIESGO}

Al momento de aplicar las estructuradas especializadas para su gestión, los bancos centrales deben distinguir entre el riesgo financiero y no financiero. Formalmente, los bancos centrales han adoptado dos rasgos básicos:

- La gestión del riesgo tendrá prioridad estratégica, aplicándose horizontal y verticalmente en la institución. 
- Dentro de un marco estandarizado se considera el riesgo operacional, reputacional y político para englobar el riesgo financiero y no financiero.

\section{POLÍTICAS ECONÓMICAS}

Las políticas económicas son un grupo de tácticas y estrategias que definen los gobiernos para dirigir un país. Dichas estrategias se implementan mediante el uso de ciertas herramientas para obtener resultados concretos. Algunas de estas herramientas son la política monetaria, la política fiscal, política cambiaria y la política comercial. Hernández las define como (2000) define: "Los tipos de política que el Gobierno, en general, sigue para lograr sus grandes objetivos nacionales de empleo, producción, estabilidad interna y externa, se llaman políticas económicas" (p. XX).

La política monetaria es el conjunto de estrategias tomadas por el Banco Central de un país para obtener los objetivos de inflación deseados por dicha institución mediante el incremento o reducción de la cantidad de dinero en circulación, movimientos en el tipo de cambio y la modificación de las tasas de interés. Mediante la política monetaria, el Banco Central intenta tener impacto en el país controlando la oferta de dinero y así cumplir con sus objetivos macroeconómicos, conservando la inflación en niveles estables. Las decisiones relacionadas con la política monetaria se toman con base en el análisis y la observación del estado vigente y de las tendencias de la economía y del pronóstico de inflación esperada.

La política fiscal consiste en una serie de acciones para acelerar el crecimiento de un país, uso eficiente de los recursos disponibles y hasta temas de incrementar las inversiones y controlar el desempleo. Lo anterior se logra mediante una buena y eficiente recaudación de impuestos y un gasto público administrado responsablemente.

Otro instrumento de la política económica es la política cambiaria. Esta se ocupa de la normativa de la tasa de cambio de divisas y del equilibrio entre el tipo de cambio nominal y el tipo de cambio real. La política cambiaria busca ejercer control sobre el tipo de cambio que debería tener una divisa, ya que el tipo de cambio tiene efectos directos sobre múltiples aspectos de la economía de un país. Uno de estos aspectos es, sin duda, la inflación; sin embargo, también se deben tomar en cuenta las exportaciones e importaciones, lo que al mismo tiempo afecta al empleo y el crecimiento económico.

También existe la política comercial que se ocupa del manejo del conjunto de herramientas que posee el gobierno para proteger, gestionar, alterar y modificar las relaciones comerciales del país con el resto del mundo. La política comercial se encuentra dirigida a fomentar el comercio exterior y la exploración de nuevos mercados para establecer relaciones mediante acuerdos o tratados de libre comercio. A veces, se puede dar la situación de que, al perseguir varios objetivos simultáneamente, estos se pueden contradecir, por lo que se debe de contar con una integración entre las diferentes políticas, de tal forma que se lleguen a dar los efectos esperados.

Para aplicar las políticas económicas, los gobiernos se valen de una serie de instituciones que las emplean de manera directa e indirecta. Como parte de los medios directos se pueden nombrar las instituciones que conforman el sector público tales como el Banco Central, bancos comerciales públicos, ministerios y otros organismos. Por otro lado, los medios indirectos hacen referencia a los poderes tácticos como las empresas transnacionales, asociaciones de empresarios y sindicatos, los cuales disfrutan de un gran apoyo tanto económico como social.

Mediante la correcta implementación y aplicación de las políticas económicas se pueden resolver muchas situaciones adversas tales como la devaluación de la moneda, la inflación, el desempleo, la pobreza, problemas ambientales, déficit 
comercial y fiscal, etc. Paralelamente, se podría hacer otra categorización de las políticas económicas desde el punto de vista sectorial. En esta clasificación ingresan la política agraria, la política energética, la política de transportes y la política industrial. Los objetivos de esta clasificación de políticas son similares, aunque de menor escala: bajo desempleo, crecimiento económico, superávit comercial y estabilidad inflacionaria.

Es importante mencionar que una política económica que haya tenido mucho éxito en un país no necesariamente lo va a tener en otro. Esto porque muchas veces las políticas económicas van de la mano con otros aspectos como la cultura del país, sistemas políticos y jurídicos, situación geográfica y recursos disponibles.

\section{POLÍTICA MONETARIA}

Esta responsabilidad recae en el Banco Central de Costa Rica mediante la Ley 7558 de 1995, siendo el principal objetivo mantener la estabilidad de la moneda nacional, tanto interna como externamente, asegurando la conversión a otras monedas (divisas). Actualmente, existen diferentes posiciones sobre la política monetaria, de las cuales sobresalen:

- Tipo de cambio flotante. Con esta política, el Banco Central no intervendría en el mercado de las divisas. Así, la oferta y la demanda determinan el tipo de cambio. Esta política no mantendría la equidad por existir igualdad de oportunidad; por ejemplo, quienes tienen información en cuanto corresponden sus compras de divisas, podrían anticipar cambios de precios obteniendo ganancias.

- Tipo de cambio neutral. Pretende basar el precio de las divisas según el comportamiento relativo de los índices de precios internos y de los principales socios comerciales. El Banco Central intervendría en el mercado para asegurar la neutralidad del tipo de cambio. Este tipo de política monetaria recaía en la política de minidevaluaciones provocando la intervención diaria del Banco Central de Costa Rica así compensar las variaciones del mercado.

- Dolarización. Con esta política desaparecía el colón como moneda oficial de Costa Rica y, con ello, las fluctuaciones; se logra así la estabilidad interna y externa. La debilidad que presenta este modelo es que desaparecería la posibilidad de utilizar la política monetaria para promover la ocupación de los recursos productivos.

- Metas de Inflación. El objetivo de la política monetaria es la estabilidad de los precios, es decir, consiste en una flotación administrada. Para ello, el Banco Central de Costa Rica deberá mantener suficientes reservas para soportar un ataque al tipo de cambio. La principal amenaza será el desequilibrio fiscal impactando así las tasas de interés.

\section{TASA DE POLÍTICA MONETARIA (TPM)}

Esta tasa corresponde a la tasa de interés que cobra el Banco Central en las operaciones activas (préstamos) a un día plazo en el Mercado Integrado de Liquidez y lo determina la Junta Directiva del Banco Central. Cuando la inflación se está saliendo del rango definido, el Banco Central sube la tasa para mantener la inflación controlada dentro del rango en los próximos meses.

Si se busca bajar la inflación, los bancos trasladan el costo de la TPM a las tasas que cobran en sus préstamos a los clientes, restringiendo la circulación de más dinero, ya que los clientes desisten de obtener préstamos por el alto costo de los intereses. Por otro lado, si la inflación está por debajo, el Banco Central baja la TPM para que los bancos 
puedan bajar sus tasas de interés y así los clientes puedan optar por préstamos.

\section{INSTRUMENTOS PARA LA APLICAR LA POLÍTICA MONETARIA}

Los instrumentos de la política monetaria hacen referencia a todas las actividades que realiza el Banco Central en el sistema financiero para alcanzar la estabilidad de precios. A veces es muy complicado que la entidad pueda intervenir en los precios de manera directa, por lo que se establece un objetivo determinado utilizando un instrumento sobre el cual sí tiene control. Estos instrumentos utilizados por el Banco Central tienen la finalidad de ayudar a administrar la política monetaria de un país. El Banco Central de Costa Rica $(2016$, s. p.) señala que:

La política monetaria es un área de la política económica, encargada a los bancos centrales, que tiene como propósito influenciar las variables monetarias y financieras para lograr objetivos específicos, que, en el caso costarricense, se circunscriben a una inflación baja y estable.

Cuando se hace referencia a una política monetaria expansiva se habla de aumentar la cantidad de dinero en la economía. Por el contrario, cuando se desea reducir la cantidad de liquidez se aplica una política monetaria restrictiva.

Los instrumentos de política monetaria muchas veces son vistos como un conjunto de acciones que el Banco Central utiliza para controlar la inflación, el suministro de dinero y el tipo de interés. Los principales instrumentos son el encaje mínimo legal, la tasa de redescuento, operaciones de mercado abierto, tipo de cambio y la persuasión moral entre otros:

- Encaje mínimo legal: es un monto de dinero proporcional a la cantidad total de las captaciones realizadas que deben mantener todas las instituciones que se dedican a la intermediación financiera. Dicho monto debe de ser depositado en el Banco Central de Costa Rica. Al existir el encaje mínimo legal, se influye en la cantidad de préstamos otorgados por las diferentes instituciones, el dinero circulante y las tasas de interés. En la actualidad el porcentaje del encaje mínimo legal es del 15\%.

- Tasa de redescuento: es la tasa de interés que el Banco Central cobra a los demás bancos comerciales por ser prestamista de última instancia. Si la tasa de redescuento se reduce, los bancos comerciales van a pagar a un precio menor los prestamos monetarios que le hayan solicitado directamente al Banco Central. Por lo tanto, el efecto de la disminución de la tasa se podría traducir, a su vez, en una rebaja en el tipo de interés que los bancos comerciales cobran por los préstamos a terceros.

- Operaciones de mercado abierto (OMA): forman uno de los instrumentos primordiales de la política monetaria para controlar los tipos de interés, administrar la liquidez del mercado introduciendo o removiendo dinero según la necesidad y dirigir la política monetaria. Las operaciones de mercado abierto son el principal instrumento al que recurre el Banco Central para gestionar la liquidez en el sistema financiero. Las operaciones para inyectar recursos se llevan a cabo a través de subastas de crédito o compra de valores a las cuales se les llama normalmente Bonos de Estabilización Monetaria (BEM). Por otro lado, también se realizan operaciones para reducir la liquidez mediante subastas de depósitos o venta de estos valores. Cuando el gobierno adquiere títulos valores, gasta recursos financieros, comprando parte de algunas empresas. Con esta operación se dice que inyecta dinero a la economía, porque incrementa la liquidez y el financiamiento de 
las empresas. Cuando el gobierno vende valores, retira parte de los recursos monetarios para financiar algunas de sus operaciones, lo que reduciría la liquidez en el sistema.

- Tipo de cambio: es el valor que tiene la moneda nacional respecto a otras monedas extranjeras. El Banco Central puede influir en el tipo de cambio para usarlo como instrumento de política monetaria. El régimen que escoge el Banco Central puede ser fijo o flexible. El aumento del tipo de cambio representa una disminución en el costo de materias primas que vienen del extranjero y que, a su vez, significan menores costos para las empresas, lo que afecta favorablemente a la inflación. El tipo de cambio debe ser similar y estable tanto interna como externamente y no debe perturbar el nivel de desarrollo del país.

- Persuasión moral: este instrumento sirve para hacer más fuertes las relaciones entre el Banco Central y los banqueros de las instituciones del sistema financiero para que las prácticas de la Banca Central sean de mayor aceptación y mejor cumplimiento por parte de los bancos comerciales y otras instituciones.

\section{RELACIONES FINANCIERAS INTER- NACIONALES}

En general, el Banco Central de cada país es el que lo representa ante cualquier institución financiera a nivel internacional. Las relaciones económicas internacionales han sufrido muchos cambios como resultado de las variaciones que se han presentado en la economía mundial y la aparición de múltiples factores de naturaleza económica y política. Es así como se determina que las relaciones económicas internacionales son un agregado de las relaciones económicas internas sujetas a la actividad económica externa con una gran influencia de las relaciones políticas que crean los diferentes gobiernos.

Las relaciones económicas internacionales son parte del deseo que tienen los diferentes países de conservar el intercambio comercial, diplomático, cultural y las relaciones políticas a nivel internacional; pero, al mismo tiempo, permiten que las empresas lleven a cabo sus actividades y operaciones sobre la base de leyes definidas y protección de sus intereses. Estas actividades se desenvuelven en torno a las relaciones comerciales internacionales, la integración económica y las relaciones monetarias y financieras internacionales. Estas han de desarrollarse sin desconocer los vínculos diplomáticos entre naciones ni mucho menos el contexto global en que se sustenta la dinámica económica.

La principal institución financiera a nivel global es el Fondo Monetario Internacional. Esta institución fue creada en 1946 y tiene como objetivo principal promover la cooperación monetaria entre los países y hacer más fácil el crecimiento del comercio internacional a través de un sistema de pagos multilaterales para las transacciones y la reducción de barreras en el comercio internacional.

Los miembros del FMl deben aceptar y comprometerse a tener mucha disciplina en términos de tipos de cambio y evitar ponerle trabas al comercio internacional. Mishkin (2008) indica que: "El FMl se dio a la tarea de promover el crecimiento del comercio mundial mediante el establecimiento de reglas para el mantenimiento de tipos de cambio fijo haciendo préstamos a países que estaban experimentando dificultades en la balanza de pagos" (p. 466).

Las principales funciones del Fondo Monetario Internacional son:

- Promover la participación monetaria internacional por medio de una institución que 
suministre mecanismos de asesoría y colaboración en materia de problemas monetarios.

- Alentar la estabilidad de los tipos de cambio y cerciorarse de que las transacciones entre sus países miembros sean claras.

- Ayudar a la expansión y el crecimiento equitativo del comercio internacional y promover y mantener altos niveles de empleo e ingresos reales y asegurar que los factores de producción de todos los países asociados sean usados de una manera eficiente.

- Establecer un sistema multilateral de pagos para las transacciones realizadas entre los países.

- Dar una imagen confianza a los estados participantes al tener disponibles para ellos recursos financieros, proporcionando la oportunidad de corregir los problemas a nivel de balanzas de pagos sin tomar medidas que pudieran comprometer la estabilidad del país.

A nivel regional existen otras instituciones como el Consejo Monetario Centroamericano. Dicha institución se fundó bajo el Acuerdo para el Establecimiento de la Unión Monetaria Centroamericana en 1964. Su objetivo principal es respaldar el proceso de integración monetaria y financiera de la región, dentro de un marco de estabilidad macroeconómica.

Está compuesto por los presidentes de los bancos centrales de Costa Rica, El Salvador, Guatemala, Honduras, Nicaragua y por el Gobernador del Banco Central de República Dominicana. El Consejo Monetario Centroamericano (2015) define lo siguiente: "El Consejo es un órgano del Subsistema de Integración Económica del Sistema de Integración Centroamericana, con carácter de Consejo Sectorial de Ministros, con autonomía funcional en el ejercicio de sus competencias" (s. p.). El Consejo Monetario Centroamericano también contribuye al fortalecimiento de la estabilidad monetaria de la región, impulsa la investigación económica regional, promueve la cooperación entre los bancos centrales miembros y pone a disposición estadísticas económicas.

El Banco Central de Costa Rica siempre ha mantenido relación con todos los demás bancos centrales de la región para mantener inversiones a nivel de reservas internacionales, para brindar apoyo en investigaciones económicas que se realicen y para llevar a cabo operaciones de convenios comerciales. También, la entidad puede formalizar operaciones crediticias de dinero con otros, mediante el depósito de reservas monetarias internacionales y operaciones que se realizan por medio de pagos electrónicos que ayudan a hacer más rápidos los trámites entre el Banco Central y otros bancos.

\section{ACUERDO DE BASILEA}

En el año 1975 fue establecido el Comité Basilea, conformado por los presidentes de los bancos centrales de los países más industrializados y cuyo fin se refleja en la necesidad de establecer normas prudenciales de supervisión y regulación bancaria en el mundo, siendo su objetivo principal la "detección temprana". El Comité Basilea se encarga de formular normas y lineamientos generales de supervisión y realiza recomendaciones sobre las prácticas de supervisión a las autoridades nacionales.

Las recomendaciones se dan sobre la legislación y regulación bancaria, con el fin de crear estándares internacionales y establecer los requerimientos de capital necesario para asegurar la protección de las entidades bancarias frente a los riesgos financieros y operativos. Esta supervisión se intenta lograr a través de tres pautas: 
- Intercambiando información con respecto a las disposiciones nacionales sobre supervisión.

- Perfeccionando la eficiencia de las técnicas de supervisión de la banca internacional.

- Estableciendo normas mínimas para la adecuación del capital.

Para el año de 1998 se publica el primer documento conocido como Acuerdo de Capital de Basilea (Basilea I), con el fin de lograr la homogeneidad en la forma de medir la adecuación de capital. Este fue modificado en el año 2001 se publicó una propuesta para realizar el Acuerdo de Basilea Il siendo los aspectos más importantes:

- $\quad$ Requisitos mínimos de capital.

- Proceso de revisión del supervisor.

- Disciplina de mercado.

Los acuerdos de Basilea se constituyen de veinticinco principios, los cuales son adaptados por las diferentes estructuras financieras.

\section{REDUCCIÓN DEL ENDEUDAMIENTO EN EL EXTRANJERO}

Este comportamiento se basa en tres factores claves de los mercados financieros, los cuales se detallarán a continuación.

\section{CAMBIOS NORMATIVOS, BASADOS EN LAS RE- GULACIONES RESTRICTIVAS SOBRE EL ENDEU- DAMIENTO EXTERNO}

- El Banco Central, en el año 2011, aprobó un 15\% de encaje sobre los préstamos, obligando a las entidades a reservar en el Banco Central una parte considerable de esos préstamos sin percibir algún tipo de pago de interés.

- Para el 2017, el Banco Central estableció que cada entidad financiera definiera la razón de posición lactivos en dólares menos los pasivos en dólares) de la moneda extranjera en términos del capital base (incluye acciones, utilidad acumulada entre otross), siendo que anteriormente se calculara sobre el patrimonio.

\section{UN MAYOR COSTO DE FONDEO}

- Al existir menos fondeo externo, inclina la balanza a una menor demanda de dólares, provocando devaluaciones en la moneda. Esto se da por el aumento de las tasas de interés internacionales.

- La llegada de Trump al poder provocó el accionar de la Reserva Federal de Estados Unidos, ajustando el costo del dinero en tres ocasiones.

- El nivel de riesgo país provocó el aumento de las tasas de interés en el extranjero, aumentando asi l a prima de riesgo que de pagar el país.

\section{MENOR DEMANDA DE PRÉSTAMOS EN MONE- DA EXTRANJERA}

- Producto del aumento del valor de la moneda extranjera, los bancos incentivaron su colocación en el mercado de préstamos en colones reduciendo así el fondeo exterior (La Nación, 2017).

\section{EL PAPEL DE LA SUGEF EN LA ECO- NOMÍA DEL PAÍS}

La Superintendencia General de Entidades Financieras (SUGEF) durante sus primeros años 
funcionó como un departamento del Banco Central de Costa Rica, denominado Auditoría General de Bancos (AGB). Es en el año 1995 que se establece la imagen regulatoria de la SUGEF, siendo este el ente supervisor encargado de velar por la estabilidad, la solidez y el funcionamiento eficiente del sistema financiero nacional. Dentro de sus funciones se encuentran las siguientes:

- Velar por la estabilidad, la solidez y el funcionamiento eficiente del sistema financiero nacional.

- Fiscalizar las operaciones y actividades de las entidades bajo su control.

- Dictar las normas generales que sean necesarias para el establecimiento de prácticas bancarias sanas.

- Establecer categorías de intermediarios financieros en función del tipo, tamaño y grado de riesgo.

- Fiscalizar las operaciones de los entes autorizados por el Banco Central de Costa Rica a participar en el mercado cambiario.

- Dictar las normas generales y directrices que estime necesarias para promover la estabilidad, solvencia y transparencia de las operaciones de las entidades fiscalizadas.

- Presentar informes de sus actividades de supervisión y fiscalización al Consejo Nacional de Supervisión del Sistema Financiero.

- Cumplir con cualesquiera otras funciones y atributos que le correspondan, de acuerdo con las leyes, reglamentos y demás disposiciones atinentes.

\section{SISTEMA NACIONAL DE PAGOS ELECTRÓNICOS (SINPE)}

En la actualidad, con el desarrollo de la Banca 3.0 o el mismo FINTECH, las instituciones financieras pueden y deben aprovechar la tecnología y la innovación, para desarrollar y poner al alcance de sus clientes productos y servicios financieros que faciliten las transacciones financieras. Esto se logra no solamente propiciando la inmediatez de su realización, sino evitando que la clientela realice filas o destine tiempo innecesario visitando las instalaciones físicas de los intermediarios financieros.

Para esto el Banco Central de Costa Rica ha desarrollado un portal financiero que integra y articula el sistema de pagos costarricense o comúnmente denominado: Sistema Nacional de Pagos Electrónicos (SINPE).

Para el Banco Central de Costa Rica (2019, s. p.): El Sistema de Pagos es el conjunto de instrumentos, procedimientos y sistemas electrónicos que permiten la transferencia y circulación del dinero entre agentes (personas e instituciones públicas y privadas) en la economía. Un sistema de pagos que funcione adecuadamente y que sea seguro, favorece el desarrollo de la actividad económica de un país.

Incluso, mediante el SinpeMóvil se pueden transferir, diariamente, hasta cien mil colones sin costo para el cliente, por medio de un mensaje de texto o por aplicaciones u páginas web de instituciones financiaras.

\section{REGISTRO DE ACCIONISTAS}

Para finalizar, es de suma importancia mencionar que, derivado de diferentes iniciativas nacionales e internacionales, todas relacionadas con la 
transparencia, fiscalidad y reconocimiento de cargas impositivas, el 1 de marzo del 2019, entró en vigencia el registro de accionistas y beneficiarios finales, después de aprobarse la ley para mejorar la lucha contra el fraude fiscal.

Tanto para el Ministerio de Hacienda, el Banco Central de Costa Rica y el Instituto Costarricense sobre Drogas, tendrán acceso a más información, particularmente porque deberán reportarse anualmente o bien cuando se supere ese porcentaje, los socios quienes cuenten con una participación igual o mayor a un $15 \%$ del capital social.

\section{CONCLUSIONES}

Se pudo determinar, durante el desarrollo de este trabajo, que Costa Rica posee y ha venido evolucionando un sistema de banca central y comercial muy avanzado, estructurado y responsable en los aspectos más importantes. Las políticas y controles del Banco Central de Costa Rica fueron vitales para que el país resguardara sus intereses económicos en tiempos de crisis inclusive tal y como sucedió en la del 2008. En ese año sucedió la crisis inmobiliaria; debido a los controles que deben cumplir los bancos comerciales, para dar crédito, se evitó que Costa Rica pasara por alguna situación similar. Estos controles vienen emitidos desde el banco central por medio de la Superintendencia General de Entidades Financieras (SUGEF).

Otro ejemplo de la aplicación de las políticas económicas fue el incremento de la planilla del estado, cuando el gobierno de Oscar Arias Sánchez decidió contratar más empleados públicos en medio de la crisis que inició en el 2008 para así evitar una recesión y que la economía pudiera seguir incentivándose y creciendo. Esa fue una política expansiva que generó resultados en el corto plazo. Más atrás en el tiempo, en el gobierno del presidente León Cortes Castro 1930-1934, hubo un ejemplo importante de la aplicación de la políticas económicas, cuando se comenzó a incrementar la obra pública, esto con el fin de emplear obreros y que con los salarios de los mismos la economía se reactivara.

Los casos anteriormente citados, aunque no fueron estudiados en este trabajo, son importantes a tomar en cuenta, ya que se vinculan con el tema en estudio, a la actualidad. Así, resulta interesante, como parte de las conclusiones finales, dar ejemplos claros acerca de acciones implementadas a nivel macro, a nivel país por algún gobierno a lo largo de la historia y, con esto, ver la aplicación de las políticas monetarias y controles bancarios en panoramas reales.

Casos como podrían comentarle y traerse a discusión con múltiples ejemplos, esto daría una perspectiva real de la importancia de la banca central de un país y sus diferentes funciones.

En términos generales, Costa Rica posee un sistema bancario bastante desarrollado, que a pesar de lo pequeño de su mercado, ha demostrado estar a la altura. Esto lo logra desarrollando políticas que han permitido que los intermediarios financieros sean competitivos, que el país haya sido y sea competitivo en términos del comercio internacional, uno de los objetivos más importantes a cumplir por un país, ya que esto es clave para el desarrollo económico.

La banca se mueve al ritmo de los cambios mundiales que ha traído la globalización, tal y como lo demuestra el hecho de haber cambiado el panorama bancario nacional al permitir la apertura de la banca y abriéndose a la posibilidad de competencia privada. Este es un beneficio principalmente para el consumidor costarricense de servicios financieros.

El Banco Central debe estar vigilante en temas de control de los índices cruciales en la economía, tales como la inflación y el IPC, además de ayudar a mantener tasas de interés estables y prudentes. Todo esto con el fin de mantener una buena 
imagen ante organismos internacionales y así mantener puertas abiertas a la hora de solicitar créditos a estos diferentes entes.

Además, el Banco Central debe mantener las políticas de control dirigidas a la banca comercial con el fin de evitar caer en crisis o recesiones económicas. De esta forma se maneja un riesgo tan mínimo como se pueda en el negocio bancario. Cabe destacar que el concepto riesgo es uno de los factores más importantes a controlar y del cual depende que Costa Rica tenga un sistema bancario nacional estable y sano.

Por último, es posible concluir que el trabajo en conjunto, fuerte y arduo tanto de la banca central como la banca comercial de nuestro país, logró que el sistema bancario nacional se constituyera como uno de los grandes pilares de la economía costarricense, sustentado en bases fuertes y confiables, de la mano de profesionales competentes que han permitido al país surgir en todas las áreas tanto sociales, económicas, tecnológicas, permitiéndole obtener un nivel de desarrollo elevado con respecto a la región.

\section{REFERENCIAS}

Banco Central de Costa Rica. n.d. Banco Central de Costa Rica. http://www.bccr.fi.cr/politica_monetaria/ (accessed 2016 йил 13-Noviembre).

Banco Central de Costa Rica. 20 de Marzo de 2019. https://www.bccr.fi.cr/seccion-sobre-bccr/gobierno-corporativo/organigrama (accesado el 20 de marzo de 2019).

Banco Central de Costa Rica. Sistema de pagos. 20 de Marzo de 2019. https://www.bccr.fi.cr/seccion-sistema-de-pagos/sistema-de-pagos (accesado el 20 de marzo de 2019).

Banco Central Europeo. Banco Central Europeo. 10 de abril de 2016. http://www.ecb.europa.eu/ecb/ educational/hicp/html/index.es.html (último acceso: 20 de octubre de 2016).
Consejo Monetario Centroamericano. Consejo Monetario Centroamericano. 1 de marzo de 2015. http://www.secmca.org/Acerca_CMCA_Creacion.html (accessed 2016 йил 16-Noviembre).

Enciclopedia Financiera. Enciclopedia Financiera. n.d. http://www.enciclopediafinanciera.com/sistemafinanciero.htm (accesado el 27 de octubre de 2016).

Hernández, Carlos. Banca Central. San José: Editorial Universidad Estatal a Distancia, 2000.

La Nación. La Nación. 27 de octubre de 2017. https:// www.nacion.com/economia/banca/bancos-ticos-acuden-menos-al-extranjero-para-financiarse/2HT6DD7IQFBSTAEOXSOLHARRXE/story/ (último acceso: 26 de Junio de 2018).

Mishkin, Frederic S. (2008). Moneda, banca y mercados financieros. Ciudad de México: Pearson.

República de Costa Rica. (1995). Ley Orgánica del Banco Central de Costa Rica. San José, Costa Rica: Asamblea Legislativa.

SUGEF. 24 de junio de 2018. https://www.sugef.fi.cr/ sobre_sugef/objetivos_y_funciones/

Recibido: 12 de febrero de 2018

Aceptado: 08 de marzo de 2019 